포유중인 모돈에서 성선자극호르몬 투여 및 예정시각 인공수정이

\author{
발정재귀 및 번식성적에 미치는 영향 \\ 유재원* · 조규호* . 손중호** . 김연수*** . 정기화*** . 김인철* \\ 농촌진흥청 축산과학원*, 노아바이오텍**, 진주산업대학교***
}

\title{
Effect of Administration of Gonadotropin and Scheduled Fixed-time Insemination on Onset of Estrus and Reproductive Performance in Lactating Sows
}

\author{
J. W. Ryu*, K. H. Cho*, J. H. Son**, Y. S. Kim***, K. H. Chung*** and I. C. Kim*
}

National Institute of Animal Science, Korea*, Noah Biotech**, Chinju National University***

\begin{abstract}
This study was to investigate the effectiveness of pre-weaning injection of gonadotropin and scheduled fixed-time insemination on sow fertility. Sows were randomly assigned to receive gonadotropin 2 days before weaning, 1 day after weaning or none as control.

In gonadotropin treated groups, half of sows were inseminated twice at 24 and 36 hours after onset estrus and half of sows were inseminated twice at scheduled fixed-time. Weaning to onset of estrus was the shortest in lactating sows injected with gonadotropin prior to weaning. Liter size was significantly higher in AI groups after detection of estrus, compared to fixed-time AI group.

Results of these experiments indicated that injection of gonadotropin in lactating sows could initiate the final follicular development, and has potential to enhance the reintegration of estrus. Further researches are needed to define the relationship between reduced interval of wean to onset estrus and enhanced fertility in lactating sows.
\end{abstract}

(Key words : Synchronization of estrus, Gonadotropin, Sows, Fixed-time AI)

$$
\text { I. 서 론 }
$$

양돈 산업에 있어서 번식은 생산성에 영향을 미치는 중요한 요인으로 번식효율 향상을 위한 다양한 연구가 보고되고 있다. 우리나라 돼지 인공수정 산업은 최근 15 년간 급속히 발전하여 2004년 말 보급율이 $80 \%$ 로 추정되고 있으며 보편적인 돼지번식 방법으로 이용되고 있다. 양돈장에서는 생산성 향상을 위하여 특정 요일
에 이유와 종부를 하는 일괄관리 체계가 널리 이용되고 있으나 경산돈에서 이유 후 발정재귀 일의 변이, 미약발정 및 무발정 등은 일관관리 체계 적용과 번식효율을 저해요인으로 작용하 고 있다. 그 중 발정재귀일의 변이와 기간을 단축하기 위한 방법으로 발정동기화에 관한 연 구가 행해지고 있다. 발정동기화는 일정한 시 기에 발정이 동시에 발현되게 하여 번식시킴으 로써 체계적인 생산관리에 매우 유용한 방법이

Corresponding author : I. C. Kim, National Institute of Animal Science, Cheonan 330-801, Korea Tel : +82-41-580-3447, Fax : +82-41-580-3450, E-mail : ryujj@rda.go.kr 
다. 포유 중인 모돈의 경우 이유 후 7일 이내 에 $90 \%$ 가 발정이 재귀 되지만 발정재귀 시기 는 개체간에 변이가 큰 것으로 보고되고 있어 (Kirkwood 와 Sechin, 1999) 처리가 간편하고 발정발현을 집중화 할 수 있는 발정동기화 방 법의 연구가 요구되고 있다.

경산돈에서 발정동기화는 이유 후 성선자극 호르몬을 투여하는 방법과 altrenogest과 같은 합성 progesterone을 이용하여 발정을 억제한 후 에 발정을 유도하는 방법이 보고되었고, 포유 중인 모돈에서 발정동기화를 위해 PG600 (400IU eCG, equine Chorionic Gonadotropin; 200IU hCG, human Chorionic Gonadotropin;)를 주사하여 발정동기화 하는 방법에 대한 연구가 보고되고 있다(Kirkwood 등, 1999; Sechin 등, 1999). 그러나 이유 시 성선자극호르몬을 주사 하여 발정동기화 하는 것은 발정재귀율은 높으 나 발정발현 및 배란 시기의 집중화 비율이 낮 은 것으로 보고되고 있다(Knox 등, 2001).

본 연구는 포유중인 모돈에서 이유 전과 후 에 성선자극호르몬을 투여하여 발정재귀일의 단축, 발정발현율, 발정발현 시간을 조사하고 예정시각 인공수정이(Fixed-time $\mathrm{AI}$ ) 번식성적에 미치는 영향을 조사하여 최적 발정동기화 방법 을 구명코자 실시하였다.

\section{․ 재료 및 방법}

\section{1. 공시재료}

포유중인 모돈은 비육돈 생산농장의 무창돈
사에서 사육중인 교잡종 $(\mathrm{L} \times \mathrm{Y}) 100$ 두를 공시하 였고, 시험축의 관리는 농장의 돼지 관리규정 에 준하여 실시하였다. 발정동기화 후 인공수 정에 이용한 정액은 듀록 3 개체의 정액을 혼합 하여 $3 \times 10^{9} / 100 \mathrm{ml}$ 농도의 액상정액을 제조하여 $17^{\circ} \mathrm{C}$ 돼지 정액 전용보관고에 보관하면서 72 시 간 이내에 인공수정에 이용하였다.

\section{2. 시험 설계}

경산돈 100 두를 공시하여 Table 1 에 나타낸 바와 같이 이유 후 발정관찰에 의한 인공수정 처리구인 대조구(Control), 성선자극호르몬 투여 시기에 따라 이유 후 성선자극호르몬 처리구 (Wean-PG) 및 이유 전 성선자극호르몬 처리구 (PG-Wean)로 구분하였고, 성선자극호르몬 처리 구 중 인공수정 방법에 따라 발정관찰 인공수 정(Detect)과 예정시각 인공수정(Fixed)으로 나누 어 각각 20두씩 공시하여 시험을 수행하였다.

\section{3. 발정동기화 및 인공수정}

시험에 공시된 돼지는 분만 후 $21 \pm 2$ 일에 이 유를 실시하였고 발정동기화는 Fig. 1에서 보는 바와 같이 Wean-PG 처리구는 이유 후 24시간 에 성선자극호르몬(PG600; PMSG 400IU와 hCG 200IU, Intervet, Holland)을 두당 $5 \mathrm{ml}$ 씩 경부 근육에 주사한 후 56시간 후에 $\mathrm{GnRH}$ (고나돈, 동방, 대한민국) $50 \mu \mathrm{g}$ 을 근육주사 하였으며, PG-Wean 처리구는 이유 48시간 전에 PG600을 $5 \mathrm{ml}$ 씩 경부 근육에 주사한 후 56시간 후에

Table 1. Treatment regimes for synchronization of estrus using gonadotropins and two different artificial insemination programs in sows

\begin{tabular}{|c|c|c|c|}
\hline & Groups & Treatment & No. of sows \\
\hline Control & & Weaning + AI & 20 \\
\hline \multirow[t]{2}{*}{ Wean-PG } & Detect & 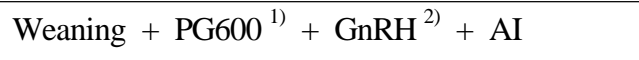 & 20 \\
\hline & Fixed & Weaning + PG600 + GnRH + Fixed time AI & 20 \\
\hline \multirow[t]{2}{*}{ PG-Wean } & Detect & PG600 + Weaning + GnRH + AI & 20 \\
\hline & Fixed & PG600 + Weaning + GnRH + Fixed time AI & 20 \\
\hline
\end{tabular}

\footnotetext{
1) PMSG 400IU + hCG 200IU (PG600, Intervet, Holland) 5ml i.m.

2) 50ug (Gonadon, Dongbang Korea) i.m.
} 
Control

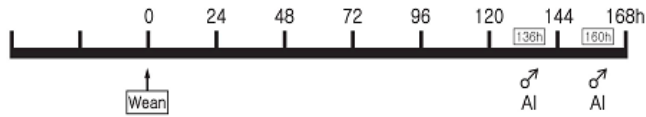

Wean-PG Detect

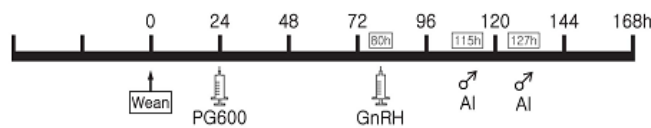

Wean-PG Fixed

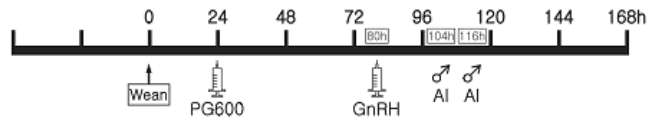

PG-Wean Detect

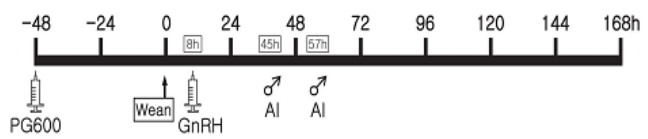

PG-Wean Fixed

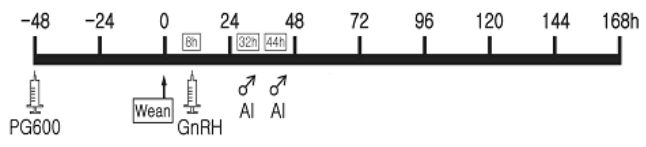

Fig. 1. Synchronization of estrus and artificial insemination in sows.

$\mathrm{GnRH} 50 \mu \mathrm{g}$ 을 근육주사 하여 발정동기화 하였 다. 발정 관찰은 이유 후부터 12시간 간격으로 수퇘지의 승가 허용여부로 확인 하였다. 인공 수정은 대조구, Wean-PG Detect 및 PG-Wean Detect 처리구에서 수퇘지 승가 확인 후 24 및 36시간에 2회 실시하였고, Wean-PG Fixed 및 PG-Wean Fixed 처리구는 GnRH주사 후 24 및 36 시간에 예정시각 인공수정을 2회 실시하였다.

\section{4. 통계분석}

결과에 대한 통계적 분석은 SAS GLM (General Linear Model)을 이용하였고, 처리구 간의 유의성검정은 최소자승 평균을 이용하였 다.

\section{III. 결과 및 고찰}

포유 중인 모돈에서 이유 전과 후에 성선자 극호르몬을 투여한 후 발정재귀율을 조사한 결
과는 Table 2에 나타난 바와 같다. 이유 후 성 선자극호르몬을 투여한 처리구는 7일 이내에 $90 \%$ 의 발정재귀율을 나타낸 반면 이유 전 성 선자극호르몬을 투여한 처리구는 $75 \%$ 의 발정 재귀율을 나타내어 이유 전 처리구의 발정발현 율이 낮았으나 유의적인 차이는 없었다. 이유 후 발정재귀에 영향을 미치는 요인으로는 모돈 의 영양상태, 계절, 수퇘지와 접촉 및 산자수 등이 보고되었다(Estienne 등, 1998, 2006). 포 유자극은 시상하부에서 $\mathrm{GnRH}$ 분비를 억제하 고, 이로 인해 뇌하수체 전엽에서 $\mathrm{FSH}$ 와 $\mathrm{LH}$ 의 분비가 억제되어 발정은 발현되지 않는다. 이유는 포유자극에 의해 억제 되었던 $\mathrm{GnRH}$ 분 비량을 증가시키며 혈액 내 LH 농도를 증가시 켜 난포를 발육시킨다(Palmer, 1965; Gooneratne, 1986).

사료의 급여 형태와 모돈의 영양 상태는 발 정재귀에 영향을 주며, 모돈에 부족한 영양 수 준은 이유 후 발정재귀율을 저하시킨다. 이러 한 문제점을 개선하기 위하여 이유 시 성선자 극호르몬 투여가 발정재귀율을 개선시키는 것 으로 보고되었다(Estienne 등, 1998, 2006).

포유 중인 모돈에서 이유 전과 후에 성선자 극호르몬을 투여한 후 발정재귀 시간을 조사한 결과는 Table 3에 나타난 바와 같이 이유 전 성선자극호르몬을 투여하여 발정이 유기된 처 리구는 발정재귀 시간이 이유 후 2.0 일로 이유 후 성선자극호르몬 처리구의 3.5 일과 대조구의

Table 2. Onset of estrus after gonadotropin treatments in sows

\begin{tabular}{|c|c|c|c|}
\hline \multirow{2}{*}{ Treatment } & \multirow{2}{*}{ No. of sows } & \multicolumn{2}{|c|}{ Estrus detected } \\
\hline & & Heads & Rates (\%) \\
\hline Control & 20 & 11 & 55.0 \\
\hline Wean-PG $^{1)}$ & 20 & 18 & 90.0 \\
\hline PG-Wean ${ }^{2)}$ & 20 & 15 & 75.0 \\
\hline
\end{tabular}

1) Wean-PG; Injection of 5ml PG600 (PMSG 400IU and hCG 200IU, Intervet) i.m., 24 hours after weaning, followed by administration of 50ug GnRH i.m., 56 hours post PG600

2) PG-Wean; Injection of 5ml PG600 i.m., 48 hours before weaning, followed by administration of 50ug GnRH i.m., 56 hours post PG600 
Table 3. Administration of gonadotropin before or after weaning on reintegration of estrus in sows

\begin{tabular}{ccc}
\hline Treatment & $\begin{array}{c}\text { No. of sows } \\
\text { detected }\end{array}$ & $\begin{array}{c}\text { Wean to estrus } \\
\text { (days) }^{3)}\end{array}$ \\
\hline \hline Control (A) & 11 & $4.2 \pm 3.5^{\mathrm{a}}$ \\
Wean-PG $^{1)}$ (B) & 18 & $3.5 \pm 2.7^{\mathrm{b}}$ \\
PG-Wean $^{2)}$ (C) & 15 & $2.0 \pm 2.9^{\mathrm{c}}$ \\
A-B & & 0.7 \\
A-C & & 2.2 \\
B-C & & 1.5 \\
\hline
\end{tabular}

1) Wean-PG; Injection of 5ml PG600 (PMSG 400IU and hCG 200IU, Intervet) i.m., 24hours after weaning, followed by administration of $50 \mu \mathrm{g}$ GnRH i.m., 56hours post PG600

2) PG-Wean; Injection of $5 \mathrm{ml} \mathrm{PG600} \mathrm{i.m.,} \mathrm{48hours}$ before weaning, followed by administration of 50ug GnRH i.m. 56hours post PG600

3) $\mathrm{LSM} \pm \mathrm{SE}$

a, b, c Different superscripts are significant differences $(\mathrm{P}<0.01)$
4.2일 보다 발정재귀 시간이 유의적으로 단축 된 것으로 나타났다 $(\mathrm{P}<0.01)$. 또한 이유 후 성 선자극호르몬의 투여는 대조구 보다 발정재귀 시간을 0.7 일 단축시키는 것으로 조사되었다 $(\mathrm{P}<0.01)$.

발정동기화 처리방법에 따른 발정발현 양상 은 Fig. 2에 나타난 바와 같다. 이유 후 발정재 귀는 대조구의 경우 3 일, 4 일 및 5 일에 $18.2 \%$, 45.5\% 및 36.4\%로 조사되었고, 이유 후 성선자 극호르몬을 처리한 구는 3일, 4일 및 5일에 $61.1 \%, 36.1$ 및 $2.8 \%$ 이였으며, 이유 전 성선자 극호르몬 투여구는 1 일과 2 일에 $15.8 \%$ 와 $84.2 \%$ 로 2 일에 $100 \%$ 가 발정이 재귀된 것으로 조사되었다.

포유 중인 모돈에서 난소 내 난포발달은 포 유 초기에는 많은 수의 작은 난포와 소수의 중 간크기 난포들이 발달하고 이후 작은 난포들은 중간 또는 큰 난포로 발달하며 이것 들은 배란 되지 않고 폐쇄난포로 퇴화 한다. 포유중인 모 돈에서 외인성 성선자극호르몬은 난포발육을 촉진할 수 있으며, 이유시에 난소 내에 발달된 난포의 존재는 발정재귀 시간을 단축할 수 있 는 것으로 보고되었다(Britt 등, 1985). 이유를

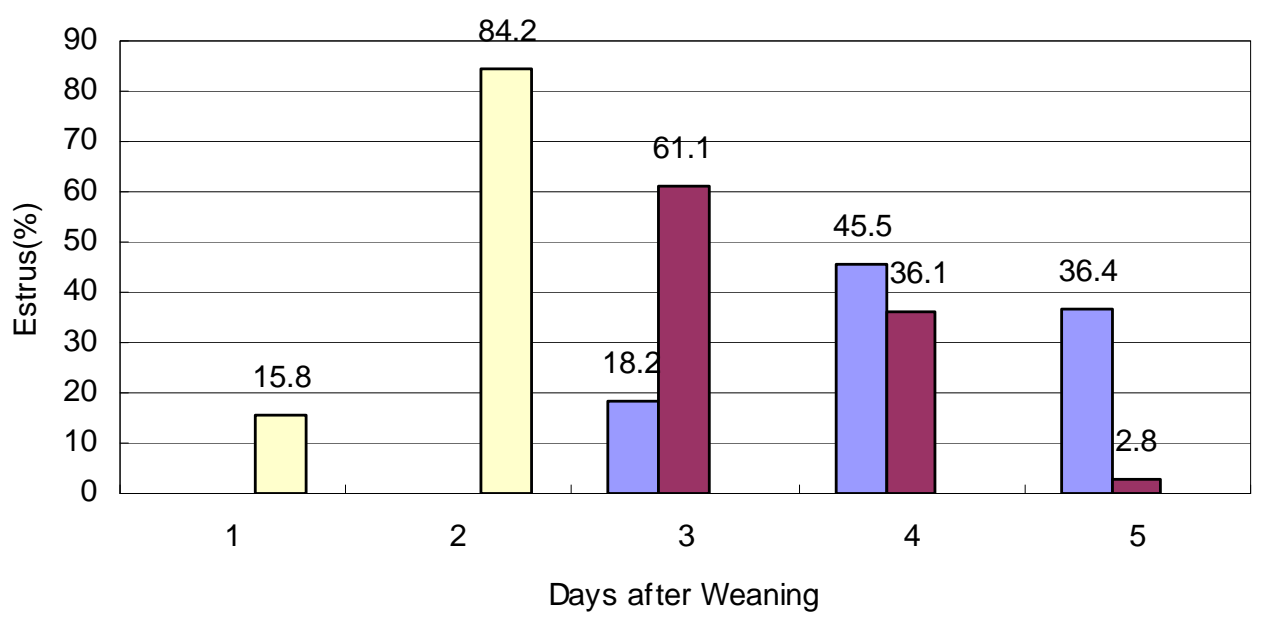

$\square$ Control $\square$ PG600 after Weaning $\square$ PG600 before Weaning

Fig. 2. The interval from weaning to standing estrus. Sows were injected with PG600 at 2 days before or 1day after weaning. 
전 후 하여 성선자극호르몬을 투여하는 것은 발정재귀율을 높이고 이유 후 발정재귀까지의 기간을 단축시킨다는 결과는 다수의 학자들에 의해 보고되었다(Bates 등, 1991; Saoulidis 등, 1995; Kirkwood 등, 1998). Estienne 등(2006)은 포유모돈에서 제한 급여를 하였을 경우 무제한 급여한 시험구에 비해 발정재귀 시간이 길었으 나 성선자극호르몬을 주사할 경우 무제한 급여 구와 발정재귀 시간은 차이가 없는 것으로 보 고하였다. Rensis 등(2003)은 이유 2일전과 이유 당일에 성선자극호르몬을 투여한 결과 대조구 에 비해 이유 당일 성선자극호르몬을 투여한 처리구가 7일 이내 발정발현율이 높았으며, 이 유 2일전에 성선자극호르몬을 처리하여 발정재 귀 시간이 단축된다고 한 결과는 본 실험결과 와 유사하였다.

포유중인 모돈에서 성선자극호르몬을 이유 전 또는 이유 후 투여한 후 발정관찰 인공수정 또는 예정시각 인공수정이 분만율과 산자수에 미치는 영향을 조사한 결과는 Table 4에 나타 난 바와 같이 분만율은 45.0 75.0\%로 처리구 간에 유의적인 차이는 나타나지 않았다. 성선 자극호르몬 투여시기에 따른 산자수는 이유 후 성선자극호르몬 투여구와 이유 전 성선자극호 르몬 투여구 간에 유의적인 차이는 없었으며, 예정시각 인공수정에 따른 산자수는 이유 전
및 이유 후 성선자극호르몬 투여구에서 9.2와 8.1두로 발정관찰 인공수정구의 $11.9,10.0$ 및 대조구 11.9 두 보다 유의적으로 적었다 $(\mathrm{P}<0.01)$.

발정동기화 후 배란시간은 예정시각 인공수 정 시간을 결정하는 중요한 요인으로 인공수정 번식성적에 영향을 미친다. 돼지에서 발정 후 배란은 19 120시간에 배란이 이루어지며(Weitze 등, 1994), 평균 40시간에 일어나는 것으로 알 려져 있다(Lang 등 2004). 배란된 난자는 자성 생식기도내에서 한정된 생존시간을 가지며 배 란 후 4시간(Hunter, 1993) 또는 8시간(Waberski and Nissen, 1995) 후에 인공수정을 실시하여도 난자가 수정에 성공하였으나 배란 후 인공수정 은 난자의 노화에 의해 분만율이 감소된다 (Terqui 등, 2000).

발정이 개시 된 후 배란 전에 $\mathrm{LH}$ 급증이 일 어나고, $\mathrm{LH}$ 급증 후에 배란이 일어나는 시간은 개체 간에 변이가 있으며, $\mathrm{LH}$ 급증 후 36 40 시간에 배란이 일어나는 것으로 알려져 있다 (Dziuk, 1977; Ellendorff and Smidt, 1984; Elsaesser, 1984). 경산돈의 경우 이유 후 발정재 귀 기간이 짧은 개체는 발정 지속 시간은 길어 지고, 이와는 대조적으로 발정재귀 기간이 긴 경우 발정지속시간은 짧아지는 것으로 보고 하 였다(Weitze 등, 1994). 또한 발정전기에 hCG를 투여하면 투여 후 40시간에 배란이 일어나는

Table 4. Reproductive performance of sows treated with PG600 and two different Al methods

\begin{tabular}{|c|c|c|c|c|c|c|}
\hline \multirow{2}{*}{\multicolumn{2}{|c|}{ Treatment }} & \multirow{2}{*}{$\begin{array}{l}\text { No. of } \\
\text { sows }\end{array}$} & \multicolumn{2}{|c|}{ Farrowing } & \multicolumn{2}{|c|}{ Litter } \\
\hline & & & Heads & $\%$ & Total $^{5)}$ & Alive \\
\hline \multicolumn{2}{|c|}{ Control } & 20 & 11 & 55 & $11.9 \pm 0.9^{\mathrm{a}}$ & $9.7 \pm 0.8$ \\
\hline Wean-PG ${ }^{1)}$ & Detect $^{3)}$ & 20 & 15 & 75 & $11.9 \pm 0.7^{\mathrm{ab}}$ & $10.9 \pm 0.7$ \\
\hline Wean-PG & Fixed $^{4)}$ & 20 & 9 & 45 & $9.2 \pm 1.0^{c}$ & $8.8 \pm 0.9$ \\
\hline PG-Wean ${ }^{2)}$ & Detect & 20 & 13 & 65 & $10.0 \pm 0.8^{\mathrm{abc}}$ & $9.0 \pm 0.8$ \\
\hline PG-Wean & Fixed & 20 & 9 & 45 & $8.1 \pm 1.0^{c}$ & $7.7 \pm 0.9$ \\
\hline
\end{tabular}

\footnotetext{
${ }^{1)}$ Wean-PG; Injection of 5ml PG600 (PMSG 400IU and hCG 200IU, Intervet) i.m. 24hours after weaning, followed by administration of 50ug GnRH i.m., 56hours post PG600

2) PG-Wean; Injection of 5ml PG600 i.m., 48hours before weaning, followed by administration of 50ug GnRH i.m., 56hours post PG600

3) Detect; Artificial insemination at 24 and 36hours after allowing mounting

${ }^{4)}$ Fixed; Artificial insemination at 24 and 36hours after GnRH administration

${ }^{5)} \mathrm{LSM} \pm \mathrm{SE}$

a, b, c Different superscripts are significant differences $(\mathrm{P}<0.01)$
} 
것으로 보고되었고(Dziuk and Baker, 1962; Hunter, 1967), PMSG와 hCG를 투여한 후 복강 경으로 관찰한 결과 37 39 및 33 48 시간에 배 란이 일어나고(Bergfeld 등, 1984; Brssow, 1990), $\mathrm{GnRH}$ 를 투여한 후 $31.2 \pm 3.3$ 시간에 배란이 일 어나며, 배란 시간은 개체간에 변이가 있는 것 으로 보고되었다. $\mathrm{GnRH}$ 는 hCG와 돼지에서 유 사한 기능을 하며, $\mathrm{hCG}$ 는 난소에 직접적으로 작용하여 $\mathrm{LH}$ 급증을 유기하고, $\mathrm{GnRH}$ 는 뇌하수 체에 작용하여 배란 전 $\mathrm{LH}$ 급증을 유도한다. 그러나 hCG는 생체 내에서 긴 반감기를 갖는 반면 $\mathrm{GnRH}$ 는 hCG에 비해 짧은 반감기를 갖는 다. 외인성 단백질인 $\mathrm{hCG}$ 를 사용하는 것은 $\mathrm{GnRH}$ 에 비해 긴 반감기로 인해 체내에서 항체 를 형성하는 원인이 될 수 있고, 반복 사용 시 $\mathrm{hCG}$ 의 작용을 저해하게 되어 사용의 제한이 발생 할 수 있다(Terqui, 2000).

발정동기화 후 hCG(Heidler 등, 1977) 또는 GnRH(Iwamoto 등, 1978) 투여 후 예정시각 인 공수정에서 1 회 인공수정 보다 2회 인공수정에 서 수태율이 높았고, 2회 인공수정은 1회 인공 수정에 비해 산자수가 증가됨을 보고 하였다.

Martinat-Botte 등(1995)은 발정동기화 후 예정 시각 인공수정에서 효율적인 번식성적을 얻을 수 있었으며, Kauffold 등(2007)은 altrenogest와 $\mathrm{GnRH}$ 를 투여한 후 24시간과 40시간에 예정시 각 인공수정을 실시한 경우, 배란은 첫 번째와 두 번째 수정 사이에 일어난 것이 $58.3 \%$ 이었고 두 번째 수정 이후에 배란된 것보다 높았다고 보고 하였다. Rensis 등(2003)은 예정시각 인공 수정에서 분만율은 대조구 보다 유의적으로 높 았으나 산자수에는 차이가 없었다고 보고하여 본 시험결과와 유사한 경향이었다. 본 연구에 서 예정시각 인공수정 처리구에서 산자수가 낮 았던 것은 배란 된 난자의 수, 배란시간과 인 공수정 시간 등의 영향에 의한 것으로 사료된다.

이상의 결과를 종합해 보면 경산돈의 발정동 기화 방법으로 이유 후 성선자극호르몬을 투여 하는 것이 효율적이며, 이유 전 성선자극호르 몬의 투여는 발정재귀일의 단축 효과를 기대 할 수 있으나 발정재귀율 개선을 위한 추가적 인 연구가 필요할 것으로 사료된다.
IV. 요 약

본 연구는 포유중인 모돈에서 이유 전과 후 에 성선자극호르몬 투여 및 예정시각 인공수정 이 번식성적에 미치는 영향을 조사하였다. 포 유중인 모돈은 대조구, 이유 전 2일 및 이유 후 1 일에 성선자극호르몬을 주사 하였다. 성선 자극호르몬을 주사한 모돈의 $1 / 2$ 은 발정확인 후 24 및 36 시간에 인공수정 하였고, $1 / 2$ 은 $\mathrm{GnRH}$ 주사 후 24 및 36시간에 각각 예정시각 인공수정 하였다.

포유중인 모돈에서 대조구, 이유 전 및 이유 후 성선자극호르몬을 투여 하여 발정재귀를 관 찰한 결과 이유 후 성선자극호르몬 투여구가 발정재귀율이 높게 조사 되였으나 유의적 차이 는 없는 것으로 조사되었다. 성선자극호르몬 투여가 발정재귀 시간에 미치는 영향을 조사한 결과 이유 전 성선자극호르몬 투여구가 발정 재귀시간이 유의적으로 짧은 것으로 조사되었 다 $(\mathrm{P}<0.01)$. 포유중인 모돈에서 성선자극호르몬 을 이유 전 또는 이유 후에 투여한 후 인공수 정을 실시한 결과 분만율과 산자수는 유의적인 차이는 없었다. 예정시각 인공수정에 따른 산 자수는 이유 전 성선자극호르몬 처리구와 이유 후 성선자극호르몬 처리구에서 예정시각 인공 수정 처리구가 발정관찰인공수정에 비하여 유 의적으로 적었다 $(\mathrm{P}<0.01)$.

이상의 결과를 종합해 보면 성선자극호르몬 은 포유중인 모돈에서 난포를 발육시킬 수 있 으며, 이유 전 성선자극호르몬의 투여는 발정 재귀일의 단축 효과를 기대 할 수 있으나 포유 돈에 있어 발정재귀율 개선과 향상된 번식성적 과의 상관 관계 정립을 위한 추가적인 연구가 필요할 것으로 사료된다.

$$
\mathrm{V} \text {. 사 사 }
$$

본 연구는 농림부 농림기술개발사업의 지원에 의해 연구되었으며 연구비 지원을 감사드립니다. 


\section{$\mathrm{VI}$. 인 용 문 헌}

1. Armstrong, T., William, A., Flowers, L. and Britt, J. H. 1999. Control of the weaning-to-estrus interval in sows using gonadotropins and prostaglandins during lactation. J. Anim. Sci. 77:25332539.

2. Bates, R. O., Day, B. N., Britt, J. H., Clark, L. K. and Brauer, M. A. 1991. Reproductive performance of sows treated with a combination of pregnant mare's serum and human chorionic gonadotropin at weaning in the summer. J. Anim. Sci. 69:894-898.

3. Bergfeld, J., Brssow, K. P. and George, G. 1984. Untersuchungen zur ovulationsdynamik und-potenz in jungsauengruppen verschiedener betriebe nach anwendung unterschiedlicher behandlungen zur ovulationsstimulation. Arch. Exper. Vet. med. 38: 735-743.

4. Britt, J. H., Armstrong, J. D., Cox, N. M. and Esbenshade, K. L. 1985. Control of follicular development during and after lactation in sows. J. Reprod. Fertil. Suppl. 33:37-54.

5. Brüssow, K. P., Ratky, J., Kanitz, W. and Becker, F. 1990. Determination of the duration of ovulation in gilts by means of laparoscopy. Reprod. Dom. Anim. 25:184-190.

6. Dziuk, P. J. and Baker, R. D. 1962. Induction and control of ovulation in swine. J. Anim. Sci. 21:697-699.

7. Dziuk, P. J. 1977. Reproduction in pigs. 3rd edition : 455-474.

8. Ellendorff, F. and Smidt, D. 1984. Endokrinologie des Sexualzyklus der Sau. Tierärztl. Umschau. 39: 429-432.

9. Elsaesser, F. 1984. Endokrinologie des Zyklus der Ovulation und des Laktationsöstrus. Züchtungskunde. 54:333-338.

10. Estienne, M. J. and Hartsock, T. G. 1998. Effect of exogenous gonadotropins on the weaning-toestrus interval in sows. Theriogenology. 49:823-828.

11. Estienne, M. J., Harper, A. F. and Horsley, B. R.
2006. Effect of PG600 on rebreeding performance in sows limit-fed during lactation. Reprod. Biol. 6:51-62.

12. Gooneratne, A. D., Kirkwood, R. N. and Thacker, P. A. 1989. Effects of injection of gonadotropinreleasing hormone on sow fertility. Can. J. Anim. Sci. 69:123-129.

13. Heidler, W., Reinhardt, L., Nowak, P. and Hhn, U. 1977. Untersuchungen zur einfachbesamung von jungsauen nach puberttsinduktion und ovulationssynchronisation. Wiss. Zeitschr. Univ. Rostock. 26: 427-430.

14. Hunter, M. G., Briggs, C., Foxcroft., G. R., McNeilly, A. S. and Tilton, J. E. 1993. Comparison of endocrinology and behavioural events during the preovulatory period in meishan and large white hybrid gilts. J. Reprod. Fertil. 97: 475-480.

15. Hunter, R. H. F. 1967. Porcine ovulation after injection of human chorionic gonadotropin. Vet. Rec. 81:2123.

16. Iwamoto, M., Hanada, A., Ogawa, T., Sato, I., Asai, T. and Kawakami, T. 1978. Induction of estrus and ovulation in prepuberal gilts with special regards to subsequent fertilization by insemination at predetermined hours after the hormonal treatments. Japan J. Anim. Reprod. 24: 39-45.

17. Johannes, K., Jochen, B., Alain, K. and Wolfgang, Z. 2007. Synchronization of estrus and ovulation in sows not conceiving in a scheduled fixed-time insemination program. Ani. Reprod. Sci. 97:8493.

18. Kirkwood, R. N. and Thacker, P. A. 1998. Use of hCG to induce a prolonged luteal phase in gilts. Int. Pig. Vet. Soc. 87.

19. Kirkwood, R. N. 1999. Pharmacological intervention in swine reproduction, Swine Health Prod. 7:29-35.

20. Knox, R. V., Rodriguez-Zas, S. L., Miller, G. M., Willenburg, K. L. and Robb, J. A. 2001. Administration of PG600 to sows at weaning and the 
time of ovulation as determined by transrectal ultrasound. J. Anim. Sci. 79:796-802.

21. Lang, A., Brandt, Y., Madej, A. and Einarsson, S. 2004. Influence of simulated stress during standing oestrus on ovulation and hormonal profile in the sow. Reprod. Dom. Anim. 39:255.

22. Martinat-Botté, F., Bariteau, F., Forgerit, Y., Macar, C., Poirier, P. and Terqui, M. 1995. Synchronization of oestrus in gilts with altrenogest : effects on ovulation rate and foetal survival. Anim. Reprod. Sci. 39: 267-274.

23. Palmer, W. M., Teague, H. S. and Venzke, W. G. 1965. Histological changes in the reproductive tract of the sow during lactation and early postweaning. J. Anim. Sci. 24:1117-1125.

24. Rensis, D., Benedetti, F., Silva, S. and Kirkwood, R. N. 2003. Fertility of sows following artificial insemination at a gonadotrophin-induced estrus coincident with weaning. Anim. Reprod. Sci. 76: 245-250.

25. Saoulidis, K. J., Kyriakis, S. K., Samouilidis, S., Tsinas, A. and Chitzios, K. 1995. Ein Beitrag zur Brunstauslosung und erhohter Fruchtbarkeit bei Zuchtsauen durch die Verabreichung gonadotroper Hormone (eCG und hCG). Teirarztl. Umschau. 52: 13-16.
26. Sechin, A., Deschamps, J. C., Lucia, T., Alexio, J. A. G. and Bordignon, V. 1999. Effect of equine chorionic gonadotropin on weaning-to-first service interval and litter size of female swine. Theriogenology. 51:1175-1182.

27. Terqui, M., Guillouet, P., Maurel, M. C. and Martinat-Botte, F. 2000. Relationship between perioestrus progesterone levels and time of ovulation by echography in pigs and influence of the interval between ovulation and artificial insemination (AI) on litter size. Reprod. Nutr. Dev. 40: 393-404.

28. Waberski, D., Sudhoff, H., Hahn, T., Jungblut, P. W., Kallweit, E., Calvete, J. J., Ensslin, M., Hoppen, H. O., Wintergalen, N. and Weitze, K. F. 1995. Advanced ovulation in gilts by the intrauterine application of a low molecular mass pronase-sensitive fraction of boar seminal plasma. J. Reprod. Fertil. 105: 247-252.

29. Waberski, D., Weitze, K. F., Gleumes, T., Schwarz, M., Willmen, T. and Petzoldt, R. 1994. Effect of time of insemination relative to ovulation on fertility with liquid and frozen boar semen. Theriogenology. 42:831-840. (접수일자 : 2007. 6. 26. / 채택일자 : 2007. 8. 8.) 